\title{
Spontaneous and Drug-Induced Concanavalin A Capping of Neutrophils from Human Infants and Their Mothers
}

\author{
RONALD G. STRAUSS ${ }^{(26)}$ AND MICHAEL J. HART \\ Department of Pediatrics, University of Iowa College of Medicine, Iowa City, Iowa, USA
}

\begin{abstract}
Summary
We investigated concanavalin A capping that occurred either spontaneously (neutrophils incubated only with buffer) or was drug induced (neutrophils with colchicine or diamide) using neutrophils obtained from the blood of newborn infants and their mothers. A greater proportion of infant and maternal neutrophils than controls formed caps spontaneously $(P<0.01)$. The percent of capped neutrophils (mean \pm S.E.) for 24 infants and their mothers was 23 \pm 3 and $39 \pm 4$, respectively, versus $13 \pm 2$ for 26 controls. Spontaneous capping was significantly decreased when neutrophils were incubated with catalase and superoxide dismutase to suggest that it was related, at least in part, to oxidation. Drug-induced capping of infant and maternal neutrophils was decreased when compared to controls $(P<0.05)$. Colchicine increased capping of control neutrophils 11.76-fold above the spontaneous value, whereas capping of infant and maternal cells was increased only 2.35- and 1.65-fold. Corresponding values for diamide were 11.94-, 2.27-, and 2.49-fold for control, infant, and maternal neutrophils, respectively. Many cellular processes are involved in capping, and the mechanisms responsible for aberrant capping of infant neutrophils remain undefined. However, this is another property that distinguishes infant neutrophils from those of older individuals.
\end{abstract}

\section{Speculation}

Functions of infant neutrophils that have been found most consistently to be abnormal are those related to plasma membrane integrity. Aberrant concanavalin A capping suggests abnormal interactions between the plasma membrane, cytoskeleton, and several metabolic processes of infant neutrophils. Further investigations of mechanisms responsible for aberrant concanavalin $A$ capping may help identify causes of the dysfunctions of infant neutrophils.

Serious infections occur frequently in newborn infants. Although several abnormalities of the body defense mechanisms of infants have been described (6), results have been contradictory, and opinion is divided regarding the relative importance of each abnormality. Neutrophils $(\mathrm{N})$ obtained from infant blood differ in many respects from those of adults (19), particularly when $\mathrm{N}$ functions dependent on plasma membrane integrity are studied such as migration, deformability, and phagocytosis (9). Several cellular processes are involved in the successful performance of membrane-dependent functions; the cytoskeleton is especially important (12). Concanavalin A (Con A) capping provides a technique to study the cytoskeleton and its interactions with the plasma membrane and other factors $(12,23)$. Furthermore, abnormalities of $\mathrm{N}$ function may be related to aberrant Con $\mathrm{A}$ capping because these conditions coexist in two disorders characterized by $\mathrm{N}$ dysfunction, Chédiak-Higashi disease (12) and glutathione synthetase deficiency (13). We investigated Con A capping of $\mathrm{N}$ isolated from the venous blood of newborn infants to further define mechanisms that may be responsible for the dysfunction of infant $\mathrm{N}$.

\section{MATERIALS AND METHODS}

Studies were approved by the local committee governing human investigations, and informed, written consent was obtained. Venous blood was collected from full-term infants and their mothers approximately $24 \mathrm{hr}$ after vaginal delivery. Adults served as controls. All subjects were healthy and were taking no medications on a regular basis.

\section{NEUTROPHIL ISOLATION}

In agreement with others (11), techniques requiring 30 to 60 min for sedimentation, gradient centrifugation, erythrocyte lysis, and washing were unsatisfactory as $\mathrm{N}$ were clumped by Con $\mathrm{A}$ and exhibited granular fluorescence. Furthermore, results were not reproducible. Accordingly, $\mathrm{N}$ were isolated rapidly using a microcentrifuge (Beckman Microfuge B, Spinco Division, Palo Alto, CA). Equal volumes of venous blood and $3 \%$ dextran (average molecular weight, 500,000) were mixed, and erythrocytes were permitted to sediment for $15 \mathrm{~min}$. One $\mathrm{ml}$ of the dextran supernatant fluid was underlaid with $0.5 \mathrm{ml}$ of a mixture of $9 \%$ Ficoll and 34\% Hypaque (refractive index, 1.3570 at room temperature) in a $1.5 \mathrm{ml}$ conical, plastic centrifuge tube. The tube was centrifuged for $60 \mathrm{sec}$, and the overlying fluid was discarded. Erythrocytes in the cell pellet were removed by hypotonic lysis, and $N$ were washed once. Centrifugation times of $3 \mathrm{sec}$ were used for these steps. Final $\mathrm{N}$ suspensions contained $2 \times 10^{6} \mathrm{~N}$ per $\mathrm{ml}$ in Krebs-Ringer phosphate buffer ( $\mathrm{pH} 7.4$ ) containing $0.2 \%$ bovine serum albumin (KRP). The final cell suspensions were similar whether obtained from infant, maternal, or control blood. Viability was always $>90 \%$ when assessed by dye exclusion. Stained slides were prepared by cytocentrifugation, and leukocyte suspensions contained approximately $90 \%$ mature N, 5\% eosinophils, and $5 \%$ mononuclear leukocytes. Erythrocytes and platelets were rarely seen.

\section{CON A CAPPING ASSAY}

Spontaneous and drug-induced capping were investigated. Spontaneous capping is that which occurs in the absence of any agent known to provoke cap formation. Reactions to evaluate spontaneous capping consisted of $0.2 \mathrm{ml}$ of $\mathrm{N}$ suspension plus 0.3 $\mathrm{ml} \mathrm{KRP.} \mathrm{To} \mathrm{study} \mathrm{drug-induced} \mathrm{capping} \mathrm{either} 0.3 \mathrm{ml}$ of colchicine (final concentration in the reaction, $2 \times 10^{-5} \mathrm{M}$ ) or $0.3 \mathrm{ml}$ of diamide (final concentration, $1 \times 10^{-4} \mathrm{M}$ ) replaced the KRP and was combined with $0.2 \mathrm{ml}$ of $\mathrm{N}$ suspension. All reactions were incubated at $37^{\circ} \mathrm{C}$ for $10 \mathrm{~min}$. Afterward, $0.02 \mathrm{ml}$ of fluoresceinlabeled Con A (Accurate Chemical and Scientific Corporation, Hicksville, NY) was added (final concentration, $12.5 \mu \mathrm{g} / \mathrm{ml}$ ), and incubation at $37^{\circ} \mathrm{C}$ was continued $4 \mathrm{~min}$. $\mathrm{N}$ were fixed for $10 \mathrm{~min}$ at $25^{\circ} \mathrm{C}$ with $0.5 \mathrm{ml}$ of $4 \%$ formaldehyde and were washed once 
with KRP. Cell pellets were resuspended to $0.025 \mathrm{ml}$ in KRP; 0.01 $\mathrm{ml}$ was placed on a slide and was covered with a cover slip. A minimum of 100 cells were examined by fluorescence microscopy to determine whether they exhibited capped or diffuse patterns of fluorescence. Results were expressed as the percent of capped cells. Capped cells were characterized by a focal area of bright fluorescence overlying a protuberance at one pole of cells otherwise weakly fluorescent (Fig. 1). Cells classified as diffuse maintained their round shape, and the entire surface emitted fluorescence (Fig. 2). Occasionally, cells with diffuse features exhibited a slightly speckled pattern of fluorescence (particularly infant and maternal $N$ ). They could not be clearly distinguished from typical diffuse cells and were included in that category.

EFFECT OF OXYGEN-

DETOXIFYING ENZYMES ON SPONTANEOUS CON A CAPPING

Two-tenths of $\mathrm{N}$ suspension was combined with either $0.3 \mathrm{ml}$ of $\mathrm{KRP}$ (standard spontaneous reaction) or $0.3 \mathrm{ml}$ of $\mathrm{KRP}$ containing 5000 units of catalase (Sigma Chemical Co., St. Louis, MO), and $150 \mu \mathrm{g}$ of superoxide dismutase (SOD) (Biotics Research Corporation, Houston, TX). Catalase plus SOD will detoxify hydrogen peroxide $\left(\mathrm{H}_{2} \mathrm{O}_{2}\right)$, superoxide anion, and hydroxyl radical. Enzymes were not studied individually because limited amounts of infant blood were available. The reactions were incubated at $37^{\circ} \mathrm{C}$ for $10 \mathrm{~min}$, and Con A labeling, fixation, and fluorescence microscopy were performed as described in the preceding paragraph.

\section{STATISTICAL ANALYSIS}

The significance of differences between infant, maternal, and control values were determined by analysis of variance with Tukey's test. In addition, infants and their respective mothers were analyzed as pairs by the sign and paired $t$ tests. Dr. Leon Bur- meister, Department of Preventative Medicine and Environmental Health, served as the statistical consultant.

\section{RESULTS}

\section{SPONTANEOUS CON A CAPPING}

A greater proportion of infant and maternal $\mathrm{N}$ formed caps than did controls when $\mathrm{N}$ were incubated only with KRP $(P<$ 0.01 ). The percent of capped $N$ (mean \pm S.E.) for 24 infants and their mothers was $23 \pm 3$ and $39 \pm 4$, respectively, versus $13 \pm 2$ for 26 controls studied simultaneously. In seven additional experiments (Table 1) the percent of capped $\mathrm{N}$ from all subjects (infants, mothers, and controls) was significantly decreased by the presence of catalase and SOD during incubation to suggest that spontaneous capping was related, at least in part, to oxidation. In particular, the excessive spontaneous capping of infant and maternal $\mathrm{N}$ seemed to be primarily a consequence of oxidation because the enzymes had a relatively greater effect on infant and maternal $\mathrm{N}$ and reduced spontaneous capping for all subjects to nearly identical levels. In five additional studies, heat-inactivated (boiling water bath for $10 \mathrm{~min}$ ) catalase and SOD were unable to prevent spontaneous capping (data not shown).

\section{CON A CAPPING INDUCED BY COLCHICINE}

Incubation of $\mathrm{N}$ with colchicine resulted in an increased $(P<$ $0.01)$ percent of capped cells from all subjects when compared to incubation with KRP (Table 2). However, the increase of control $\mathrm{N}$ was significantly greater than that of infant and maternal $\mathrm{N}$. The poor capping response to colchicine of infant and maternal $\mathrm{N}$ was particularly striking when related to the baseline (spontaneous capping). For example, both the actual increase (colchicine $\mathrm{KRP}$ values) and the fold-increase (colchicine $\div \mathrm{KRP}$ values) of

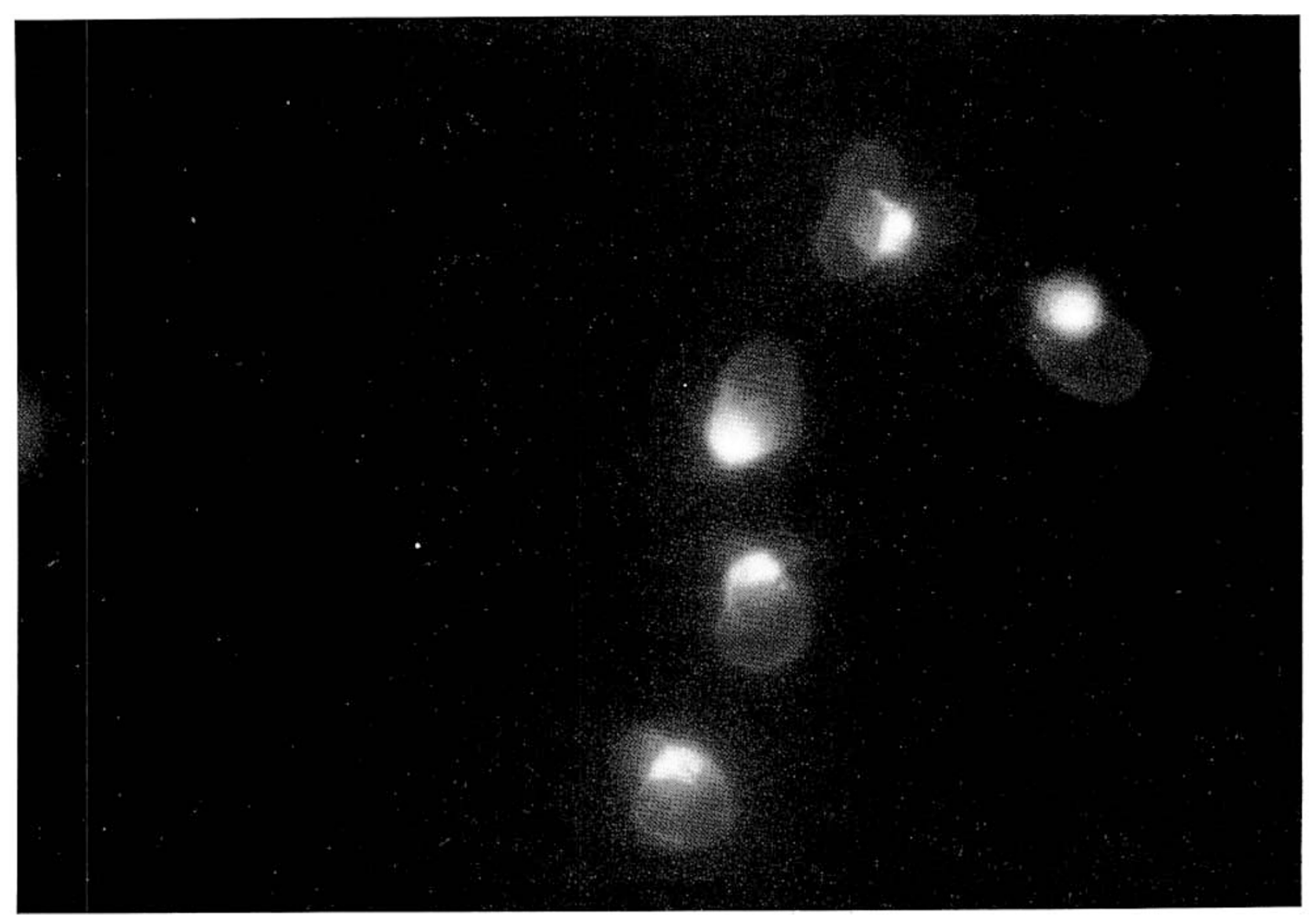

Fig. 1. Neutrophils exhibiting caps of fluoresceinated Con A. Fluorescence is brightest over a protuberance at one pole of each cell (magnification, $\times 125)$. 


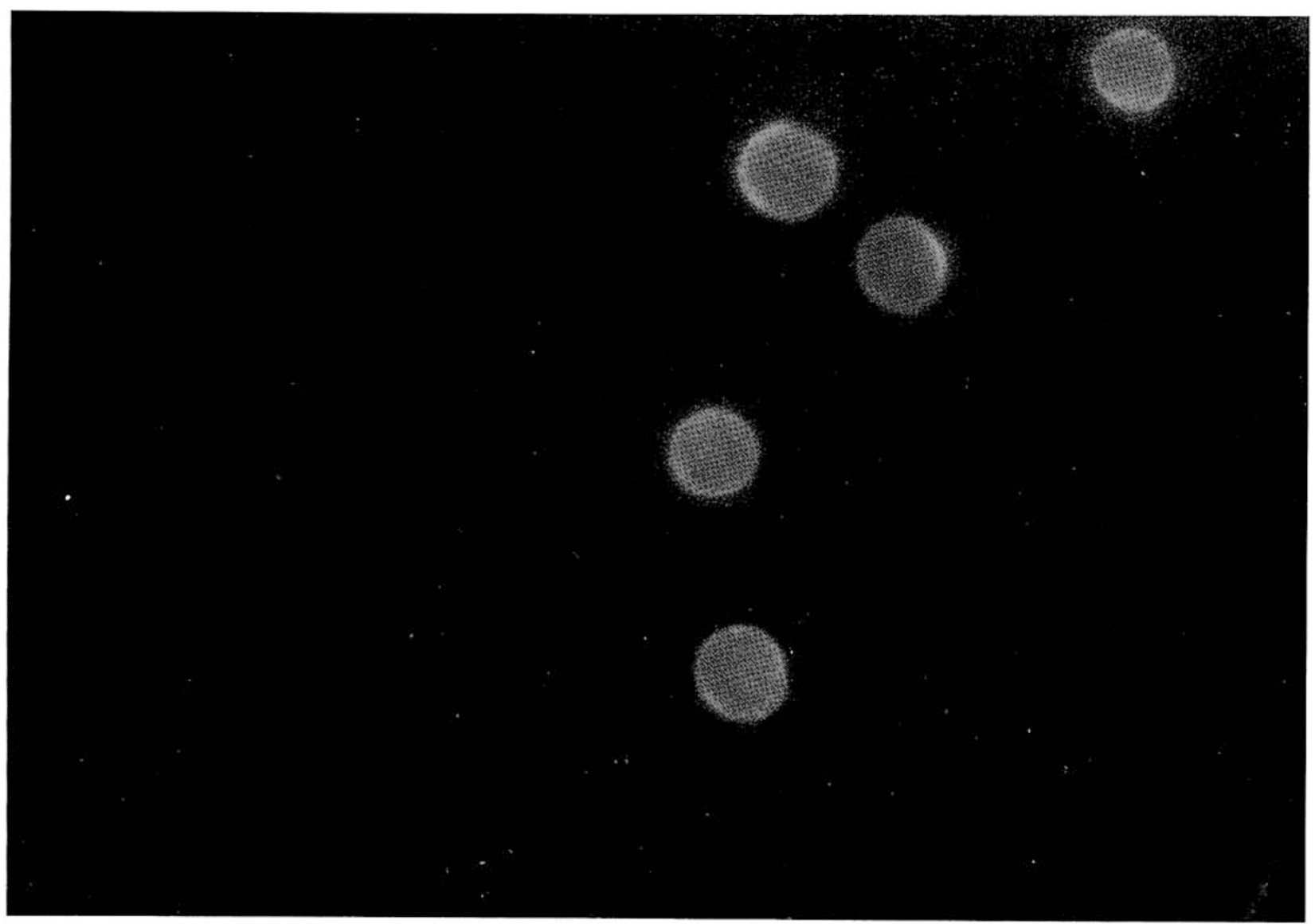

Fig. 2. Neutrophils exhibiting diffuse fluorescence. Fluoresceinated Con A molecules are distributed uniformly over the surface of each cell (magnification, $\times 125$ ).

Table 1. Effect of enzymes ${ }^{1}$ on the percent of neutrophils

\begin{tabular}{|c|c|c|c|}
\hline Conditions ( 7 experiments) & Controls & Infants & Mothers \\
\hline Neutrophils (+) KRP & $10 \pm 2^{2}$ & $13 \pm 4$ & $29 \pm 4$ \\
\hline $\begin{array}{l}\text { Neutrophils }(+) \text { KRP with } \\
\text { enzymes }\end{array}$ & $4 \pm 1$ & $4 \pm 1$ & $8 \pm 2$ \\
\hline Reduction by enzymes ${ }^{3}$ & 6 & 9 & 21 \\
\hline$P($ enzymes- $v s$-no enzyme) & $<0.01$ & $<0.05$ & $<0.01$ \\
\hline
\end{tabular}

' SOD (150 $\mu \mathrm{g})$ plus catalase (5000 units).

${ }^{2}$ Mean \pm S.E.

${ }^{3} \mathrm{KRP}$ value (-) KRP with enzymes.

capping above the baseline of spontaneously capped cells was markedly decreased (Table 2).

\section{CON A CAPPING INDUCED BY DIAMIDE}

Although diamide increased the proportion of capped $\mathrm{N}$ above the spontaneous (KRP) value for all groups of subjects, the increase was significant $(P<0.05)$ only for controls (Table 3$)$. As with colchicine, the actual increase and fold-increase of capping above spontaneous baseline values were strikingly decreased in infant and maternal $\mathrm{N}$ when compared to controls.

\section{DISCUSSION}

Con $\mathrm{A}$ binds to $\mathrm{N}$ plasma membranes and stimulates microtubular assembly, an increase in oxidative metabolism, cell migration, and granule exocytosis (7); the last requires the presence of cytochalasin B. Con A capping has been recently reviewed (12).
Table 2. Percentage of neutrophils with Con $A$ caps induced by colchicine

\begin{tabular}{lllllll}
\hline $\begin{array}{c}\text { Conditions } \\
(20 \text { experiments })\end{array}$ & Controls & Infants & Mothers & & $P^{1}$ & \\
\hline $\begin{array}{c}\text { Neutrophils (+) } \\
\text { KRP }\end{array}$ & $14 \pm 3^{2}$ & $23 \pm 3$ & $38 \pm 4$ & NS & $<0.05$ \\
$\begin{array}{c}\text { Neutrophils (+) } \\
\text { colchicine }\end{array}$ & $69 \pm 2$ & $38 \pm 3$ & $51 \pm 3$ & $<0.05$ & $<0.05$ \\
$\begin{array}{c}\text { Colchicine values } \\
(-) \text { KRP values }\end{array}$ & 55 & 15 & 13 & $<0.05$ & $<0.05$ \\
$\begin{array}{c}\text { Colchicine values } \\
(\div) \text { buffer values }\end{array}$ & 11.76 & 2.35 & 1.65 & $<0.05$ & $<0.05$ \\
\hline
\end{tabular}

\footnotetext{
' Controls-versus-infants, left column; controls-versus-mothers, right col-

${ }^{2}$ Mean \pm S.E.
} umn.

Fluoresceinated Con A binds to receptors distributed uniformly over the surface of freshly isolated, normal $\mathrm{N}$ to give a pattern of diffuse fluorescence. Within minutes of binding, Con A induces a pericentriolar assembly of microtubules. Initially, a thin layer of microfilaments is distributed evenly under the entire plasma membrane. Some investigators have reported that fluoresceinated Con A molecules spontaneously coalesce to form a single fluorescent cap when $\mathrm{N}$ are incubated in buffer (7), but the existence of spontaneous capping is debated. The conflicting findings may be related to differences in techniques of $N$ isolation that result in various degrees of membrane pertubation and cellular damage. All investigators agree that capping is greatly accelerated by 
Table 3. Percentage of neutrophils with Con A caps induced by diamide

\begin{tabular}{llllll}
\hline $\begin{array}{c}\text { Conditions } \\
(7 \text { experiments) }\end{array}$ & Controls & Infants & Mothers & \multicolumn{2}{c}{$P^{1}$} \\
\hline $\begin{array}{l}\text { Neutrophils (+) } \\
\text { KRP }\end{array}$ & $13 \pm 3^{2}$ & $26 \pm 6$ & $42 \pm 9$ & 0.5 & $<0.01$ \\
$\begin{array}{c}\text { Neutrophils (+) } \\
\text { diamide }\end{array}$ & $82 \pm 6$ & $45 \pm 8$ & $59 \pm 11$ & $<0.05$ & $<0.05$ \\
$\begin{array}{c}\text { Diamide values }(-) \\
\text { KRP values }\end{array}$ & 69 & 19 & 17 & $<0.05$ & $<0.05$ \\
$\begin{array}{l}\text { Diamide values }(\div) \\
\text { KRP values }\end{array}$ & 11.94 & 2.27 & 2.49 & $<0.05$ & $<0.05$ \\
\hline
\end{tabular}

' Controls-versus-infants, left column; controls-versus-mothers, right column.

${ }^{2}$ Mean \pm S.E.

exposing $\mathrm{N}$ to agents that produce a state of microtubular disassembly such as colchicine or to oxidants including $\mathrm{H}_{2} \mathrm{O}_{2}$ (1), tertiary butylhydroperoxide, and diamide (13). Coincident with microtubular disassembly, a protuberance appears at one pole of the $\mathrm{N}$ over which Con A molecules form a cap. Microfilaments lose their uniform pattern of distribution beneath the plasma membrane and are concentrated beneath the protuberance. In addition to requiring these interactions of plasma membrane and cytoskeleton, capping by $\mathrm{N}$ is an energy-dependent process that can be inhibited by cold temperatures and by cytochalasin B (12, 17, 23). Thus, an alteration in any of several cellular processes could lead to aberrant Con A capping.

We found Con A capping of $\mathrm{N}$ isolated from the blood of infants and their mothers to differ in two respects from that of controls studied simultaneously. First, a greater percentage of infant and maternal $\mathrm{N}$ formed caps spontaneously when incubated only in buffer than did control N. Second, two agents that promote microtubular disassembly and capping, colchicine (a drug that binds to microtubules) and diamide (an oxidant of cellular components including glutathione) induced fewer infant and maternal $\mathrm{N}$ than controls to form caps. The mechanisms responsible are undefined.

Spontaneous capping of $\mathrm{N}$ from each group of subjects during incubation with KRP can be explained, at least in part, by oxidation because the percent of capped $\mathrm{N}$ was significantly decreased when the KRP contained catalase and SOD. The excessive spontaneous capping of infant and maternal $\mathrm{N}$, in particular, seemed related to oxidation because these enzymes exhibited a relatively greater effect on these cells and lowered the baseline values of all groups to similar levels (Table 1). The following evidence suggests that $\mathrm{N}$ from infants and mothers may be particularly prone to oxidant damage and consequent spontaneous capping. Several aspects of oxidative metabolism including oxygen consumption, $\mathrm{H}_{2} \mathrm{O}_{2}$ production, hexose monophosphate shunt activity, nitroblue tetrazolium dye reduction, and superoxide anion generation have been reported to be increased in infant $\mathrm{N}$ $(19,20)$, pregnant women, or subjects taking oral contraceptives $(2,10,14)$, particularly when nonphagocytic $\mathrm{N}$ have been studied. Con $\mathrm{A}$ binding to infant and maternal $\mathrm{N}$ may enhance production of reactive molecules of oxygen. Furthermore, $\mathrm{N}$ from human infants exhibit both increased oxidative metabolism and deficient activities of glutathione peroxidase and catalase, the major enzymes responsible for detoxifying $\mathrm{H}_{2} \mathrm{O}_{2}(21)$. Finally, the viability of infant $\mathrm{N}$ in vitro is decreased when compared to controls, a finding that has been related to oxidant damage (20). However, factors other than oxidation seem to be involved in spontaneous capping because catalase and SOD were unable to completely suppress the baseline value to zero.

Three disorders lend support to the concept that spontaneous
Con A capping is related in part to oxidation. First, the increase in spontaneous capping of $\mathrm{N}$ from a patient with glutathione synthetase deficiency was decreased by vitamin $\mathrm{E}$ (antioxidant) therapy without changing underlying abnormalities of glutathione metabolism (4). Second, $\mathrm{N}$ from patients with Chédiak-Higashi disease spontaneously cap when incubated with Con $\mathrm{A}$, and microtubules fail to form after appropriate stimuli. Both capping and microtubule assembly can be improved by ascorbic acid (3, 12). The mechanism of action for ascorbic acid in this situation is debated, but it is of special interest that this drug can function as a reducing agent. Several aspects of oxidative metabolism are increased in nonphagocytic $\mathrm{N}$ from patients with Chédiak-Higashi disease (16), a situation reminiscent of that present in $\mathrm{N}$ from newborn infants. Third, $\mathrm{N}$ from rats with glutathione peroxidase deficiency were susceptible to oxidant damage, and microtubules were disassembled in $\mathrm{N}$ exposed to Con $\mathrm{A}$ (8). Although capping per se was not measured, it seems likely that spontaneous capping would have occurred as a consequence of the state of microtubular disassembly.

The failure of infant and maternal $\mathrm{N}$ to form caps to the degree expressed by controls when exposed to either colchicine or to diamide is unexplained. Colchicine induced a significant increase in the percent of capped $\mathrm{N}$ above the baseline for all groups, but the response was greater in controls. Diamide elicited an increase in capping for all groups, but it was significant only for the controls. The failure of these drugs to increase capping equally in all groups of subjects was not simply a consequence of increased spontaneous capping (elevated baseline values). It is possible that oxidant injury is related both to spontaneous and to induced cap formation. Relatively mild degrees of oxidation promote microtubular disassembly and capping. In contrast, more severe oxidant damage renders $\mathrm{N}$ incapable of cap formation. In support, Con $\mathrm{A}$ capping induced by colchicine was markedly decreased in alveolar macrophages obtained from guinea pigs exposed to hyperoxia (24). Further, in the patient with glutathione synthetase deficiency (12), colchicine elicited normal Con A capping, whereas diamideinduced capping was decreased despite the ability of both drugs to disassemble microtubules. This apparent paradox was ascribed to oxidant damage of critical cellular factors that was easily provoked by diamide due to the low concentrations of reduced glutathione in these neutrophils $(4,13)$.

Many activities of phagocytic cells are rendered defective by oxidation $(1,4,8,12,13,15,20,22,24) . \mathrm{N}$ from infants and mothers may be prone to oxidant damage, and one may speculate that infant and maternal $\mathrm{N}$ suffered varying degrees of oxidant damage before or coincident with their exposure to Con A. Mildly oxidized $\mathrm{N}$ formed caps spontaneously during incubation in KRP, whereas, those more severely damaged were incapable of capping even when exposed to colchicine or diamide. The degree of damage even to the last group of $\mathrm{N}$ was relatively mild because $>90 \%$ of $\mathrm{N}$ were viable before fixation when tested by dye exclusion. To date, it has not been possible to directly demonstrate oxidant damage in human N. Malonaldehyde, the lipid peroxidation product that is so useful for this purpose in many tissues, cannot be demonstrated in human $N(18)$.

Many cellular processes are involved in cap formation $(12,23)$, and the possibility cannot be excluded that abnormalities unrelated to oxidation may contribute to aberrant capping. For example, it has been suggested in a preliminary report (5) that decreased Con A capping of infant $\mathbf{N}$ is a developmental defect of the plasma membrane. Longitudinal studies of the capping of infant and maternal $\mathrm{N}$ and investigations of plasma membrane, cytoskeleton, and biochemical characteristics of these cells will be required to completely define the mechanisms responsible for aberrant Con A capping and to determine whether they are related to the other dysfunctions of infant $\mathrm{N}$.

\section{REFERENCES AND NOTES}

1. Baehner, R. L., Boxer, L. A., Allen, J. M., and Davis, J.: Autooxidation as a basis for altered function by polymorphonuclear leukocytes. Blood, 50: 327 (1977). 
2. Bjorksten, B., Soderstrom, T., Damber, M. G., Von Schoultz, B., and Stigbrand, $T$.: Polymorphonuclear leukocyte function during pregnancy. Scand. J. Immunol., 8: 257 (1978)

3. Boxer, L. A., Altertini, D. F., Baehner, R. L., and Oliver, J. M.: Impaired microtubule assembly and polymorphonuclear leucocyte function in the Che'diak-Higashi Syndrome correctable by ascorbic acid. Br. J. Haematol., 43: 207 (1979).

4. Boxer, L. A., Oliver, J. M., Spielberg, S. P., Allen, J. M., and Schulman, J. D.: Protection of granulocytes by vitamin $\mathrm{E}$ in glutathione synthetase deficiency. N. Engl. J. Med., 301: 901 (1979).

5. Kimura, G. M., Raghunathan, R., Leake, R. D., and Miller, M. E.: Reduced concanavalin A capping of neonatal polymorphonuclear leukocytes. Clin. Res. (Abstract), 28: 109 (1980)

6. Kroc Foundation Conference on Host Defenses in the Fetus and Neonate. Pediatrics 64 (Suppl.): 705 (1979).

7. Kuehn, C., and Van Epps, D. E.: Lectin-mediated induction of human neutrophi chemotaxis, chemokinesis, and cap formation. Infect. Immun., 29: 600 (1980).

8. McCallister, J., Harris, R. E., Baehner, R. L., and Boxer, L. A.: Alteration of microtubule function in glutathione peroxidase-deficient polymorphonuclear leukocytes. J. Reticuloendothel. Soc., 27: 59 (1980).

9. Miller, E. M.: Phagocyte function in the neonate: selected aspects. Pediatrics, 64 : 709 (1979).

10. Norden, C. W., and Reese, R.: Oral contraceptives and NBT test. N. Engl. J. Med., 287: 254 (1972)

11. Oliver, J. M.: Concanavalin A cap formation on human polymorphonuclear leukocytes induced by R17934, a new antitumor drug that interferes with microtubule assembly. J. Reticuloendothel. Soc., 19: 389 (1976).

12. Oliver, J. M.: Cell biology of leukocyte abnormalities-membrane and cytoskeletal function in normal and defective cells. Am. J. Pathol., 93: 221 (1978)

13. Oliver, J. M., Spielberg. S. P., Pearson, C. B., and Schulman, J. D.: Microtubule assembly and function in normal and glutathione synthetase-deficiency polymorphonuclear leukocytes. J. Immunol., 120: 1181 (1978).

14. Ramsdale, E. H., and Mowbray, J. F.: Positive NBT tests in pregnancy. Lancet (1973).

15. Roos, D., Weening, R. S., Voetman, A. A., Van Schaik, M. L. J., Bot., A. A. M., Meerhof, L. J., and Loos, J. A.: Protection of phagocytic leukocytes by endogenous glutathione: studies in a family with glutathione reductase deficiency. Blood, 53: 851 (1979).
16. Root. R. K.. Rosenthal, A. S., and Balestra, D. J.: Abnormal bactericidal, metabolic, and lysosomal functions of Chédiak-Higashi Syndrome leukocytes. J. Clin. Invest., 51: 649 (1972).

17. Ryan, G. B., Borysenko, J. Z., and Karnovsky, M. J.: Factors affecting the redistribution of surface-bound concanavalin A on human polymorphonuclear leukocytes. J. Cell Biol., 62: 351 (1974).

18. Strauss, R. G.: Malonaldehyde is not a suitable screening test to detect oxidation in human neutrophils. J. Clin. Pathol. (in press) (1981)

19. Strauss, R. G., and Mauer, A. M.: Formed elements of the human blood, In: L. Stave: Perinatal Physiology, Ed. 2, p. 199 (Plenum Publishing Co., New York, 1977).

20. Strauss, R. G., and Snyder, E. L.: Neutrophils from human infants exhibit decreased viability. Pediatr. Res., 15: 794 (1981).

21. Strauss, R. G., Snyder, E. L., Wallace, P. D., and Rosenberger, T. G.: Oxygendetoxifying enzymes in neutrophils of infants and their mothers. J. Lab. Clin Med., 95: 897 (1980).

22. Voetman, A. A., and Roos, D.: Endogenous catalase protects human blood phagocytes against oxidative damage by extracellularly generated hydrogen peroxide. Blood, 56: 846 (1980)

23. Williams, D. A., Lessard, J., Boxer, L. A., Rein, D., and Baehner, R. L.: Metabolic and structural requirements for concanavalin A capping in phagocytic cells. Proc. Soc. Exp. Biol. Med., 162: 34 (1979)

24. Wolff, L. J., Boxer, L. A., Allen, J. M., and Baehner, R. L.: The selective effect of hyperoxia on the guinea pig alveolar macrophage membrane. J. Reticuloendothel. Soc., 24: 377 (1978).

25. The authors thank Dr. James A. Goeken, Department of Pathology, and the other personnel of the Immunopathology Laboratory, University of Iowa Hospitals and Clinics for their assistance in using the fluorescence microscope.

26. Requests for reprints should be addressed to: Ronald G. Strauss, M.D., Department of Pediatrics, University of Iowa Hospitals and Clinics, Iowa City, IA 52240 (USA).

27. This research was supported in part by NIH Grants I ROI HDI 1964 and HL 07485. Dr. Strauss is recipient of Research Career Development Award 1 KO4 HD00255 from the National Institute of Child Health and Human Development, NIH.

28. Received for publication March 3, 1981

29. Accepted for publication June 1, 1981 